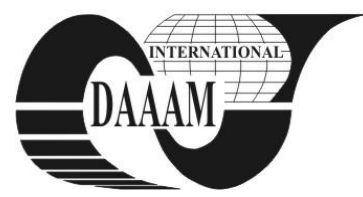

Annals of DAAAM for 2011 \& Proceedings of the 22nd International DAAAM Symposium, Volume 22, No. 1, ISSN 1726-9679 ISBN 978-3-901509-83-4, Editor B. Katalinic, Published by DAAAM International, Vienna, Austria, EU, 2011 Make Harmony between Technology and Nature, and Your Mind will Fly Free as a Bird Annals \& Proceedings of DAAAM International 2011

\title{
PARAMETERS IDENTIFICATION OF MECHANICAL BEHAVIOUR LAW FOR POLYETHER-ETHER-KETONE COMPOSITES
}

\author{
TRUFASU, D[an] - C[atalin]; BESNEA, M[aria] - A[ida] - C[ristina]; ANDREI, G[abriel] \& DIMA, D[umitru]
}

\begin{abstract}
Mechanical properties of neat poly-ether-etherketone (PEEK), reinforced PEEK with 30 (wt\%) carbon fibres (PEEK CF 30) and filled PEEK with 15.8 (wt\%) carbon nanotubes (PEEK Nano) were investigated at compression test for differing strain-rates. The G'Sell-Jonas phenomenological model was used to describe the flow curve of the PEEK composites.
\end{abstract}

Key words: mechanical law, parameters, polyether-etherketone, composites

\section{INTRODUCTION}

Poly-ether-ether -ketone polymer is a linear aromatic semicrystalline thermoplastic with excellent mechanical properties (Zhang et al., 2004). Capable of being processed on conventional thermoplastic equipment, PEEK is a high performance material and has been used as matrix for advanced polymer composites. PEEK is used in applications that need high loading for long period at high temperature without permanent deformation. However, the tensile strength of PEEK exceeds that of most usual polymers. Due to their properties, carbon fibres are the reinforcement currently used in high performance thermoplastic composite. Carbon fibres reinforced PEEK is one of the best thermoplastic composite. Otherwise, in order to improve thermal and electrical behavior, PEEK matrices are filled with carbon nanotubes. The mechanical properties of PEEK composites mostly depend on fillers and fibers reinforcement (Ogasawara et al., 2011). After the parameters identification of mechanical behaviour law the next step will be the implementation of the behaviour law in ABAQUS Software for validation.

\section{THEORETICAL}

Rheology of polymer matrix makes difficult to predict the flow curve of composite under compression test, so that a simply model could not describe well such behaviour. A constitutive equation, including involved parameters (displacement, load, time and temperature) is needed to represent the whole phenomenon, just by modifying a limited number of parameters. A global relationship that describes the rheological behaviour of polymer matrix can be expressed as follows:

$$
\bar{\sigma}=f(\lambda, \bar{\varepsilon}, \dot{\bar{\varepsilon}}, T)
$$

where: $\bar{\sigma}$ is the true stress, $\bar{\varepsilon}$ is the true strain, $\lambda$ represents material coefficients, $\dot{\bar{\varepsilon}}$ is the strain-rate, and $T$ is the absolute temperature. For the purpose of this discussion, we used a multiplicative model for semi-crystalline polymers proposed by G'Sell and Jonas (Rezgui et al., 2011; G'Sell, 1988), according to the equation (2). The applicability of G'Sell-Jonas model for semi-crystalline polymers at different strain-rates was shown by many researchers (Rezgui et al., 2011; Schoßig et al., 2008).

$$
\begin{aligned}
& \bar{\sigma}=K \times f(\bar{\varepsilon}) \times g(\dot{\bar{\varepsilon}}) \\
& f(\bar{\varepsilon})=V(\bar{\varepsilon}) \times Y(\bar{\varepsilon}) \times H(\bar{\varepsilon})
\end{aligned}
$$

$$
g(\dot{\bar{\varepsilon}})=\dot{\bar{\varepsilon}}^{m}
$$

The equation (3) can be divided into three terms: the first term $V(\bar{\varepsilon})=1-e^{-w \cdot \bar{\varepsilon}}$, refers to a Maxwell viscoelasticity up to the yield point, $w$ is the viscoelastic coefficient; the second term, $Y(\bar{\varepsilon})=1+a \times e^{-b \cdot \bar{\varepsilon}}$, describes the softening portion of the stress - strain curve, where $a$ and $b$ are softening coefficients; the third term of the equation (3) refers to the plastic strain hardening, $H(\bar{\varepsilon})=e^{h \cdot \bar{\varepsilon}^{n}}$, where $h$ and $n$ are hardening coefficients. The equation (4) describes the strainrate $g(\dot{\bar{\varepsilon}})=\dot{\bar{\varepsilon}}^{m}$, where $m$ is the sensitivity coefficient to the strain- rate. In the equation (2), $K$ is the consistency of the material.

\section{EXPERIMENTAL DETAILS AND MATERIALS}

To determine the mechanical behavior, we used the quasistatic compression test for three materials, PEEK, PEEK CF 30, and PEEK Nano. Tests were performed using an INSTRON 3369 testing machine (Fig.1). The samples were cylinders with $6 \mathrm{~mm}$ diameter and $9 \mathrm{~mm}$ height, in order to avoid material buckling during testing. Compression tests of the samples were performed at $23^{\circ} \mathrm{C}$ for three compression speed, $0.5 \mathrm{~mm} / \mathrm{min}, 5$ $\mathrm{mm} / \mathrm{min}$ and $10 \mathrm{~mm} / \mathrm{min}$, corresponding to following initial generalized strain-rate: $1 \times 10^{-3} \mathrm{~s}^{-1}, 1 \times 10^{-2} \mathrm{~s}^{-1}, 2 \times 10^{-2} \mathrm{~s}^{-1}$ (Fig. 2). We assume that the material is homogeneous and isotropic, and the coefficient of friction between specimen and the platen of the testing machine is neglected.

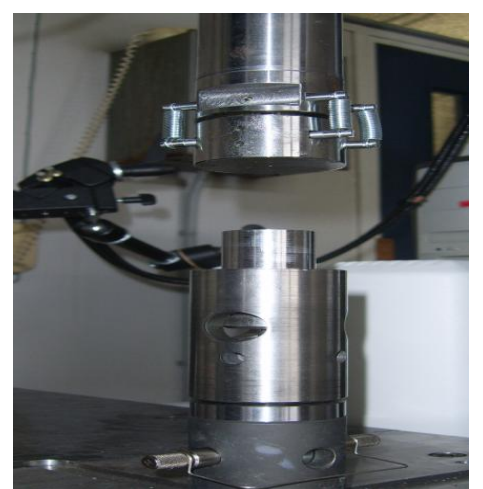

Fig. 1. Compression test device (INSTRON 3369)

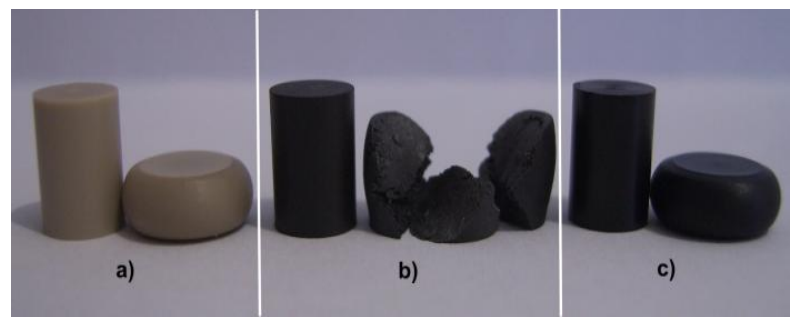

Fig. 2 Specimens before and after compression test: a) Neat PEEK ( $\mathrm{v}=0.5 \mathrm{~mm} / \mathrm{min})$; b)PEEK CF30 ( $\mathrm{v}=5 \mathrm{~mm} / \mathrm{min})$; c) PEEK Nano ( $\mathrm{v}=10 \mathrm{~mm} / \mathrm{min})$ 


\section{RESULTS AND DISCUSSION}

The flow curve, according to G'Sell-Jonas model, was found using only mechanical behavior parameters of each material (Figs. 1, 2, 3). Rheological parameters were calculated successively, taking into account the corresponding strain domain. The first parameter obtained was the sensitivity to the strain-rate, $m$. In the second step, parameters $K$ and $w$ were calculated from the stress-strain curve. Hardening coefficients $h$ and $n=2$ (G'Sell, 1988), were analyzed on the largest strain sub domain, in the third step. The yield-drop sub domain is described by the parameters $a$ and $b$, only in the case of neat PEEK. The values of the flow curve parameters for three materials, calculated on the basis of experimetal data, are shown in the Table 1.

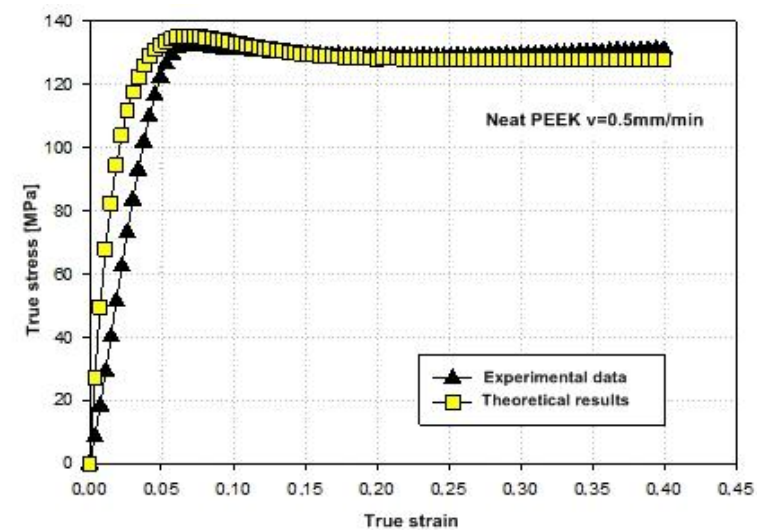

Fig. 3. Comparison between experimental and theoretical stress versus strain, for neat PEEK, at strain-rate of $1 \times 10^{-3} \mathrm{~s}^{-1}$

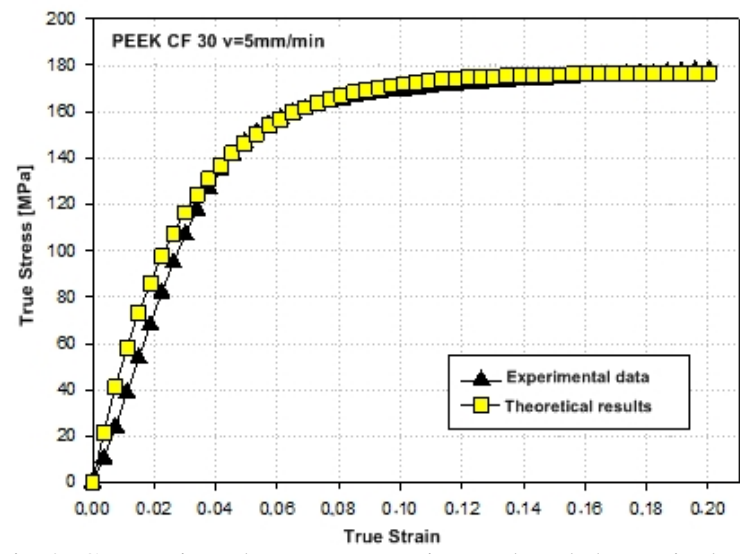

Fig.4. Comparison between experimental and theoretical stress versus strain, for PEEK CF 30, at the strain-rate of $1 \times 10^{-2} \mathrm{~s}^{-1}$

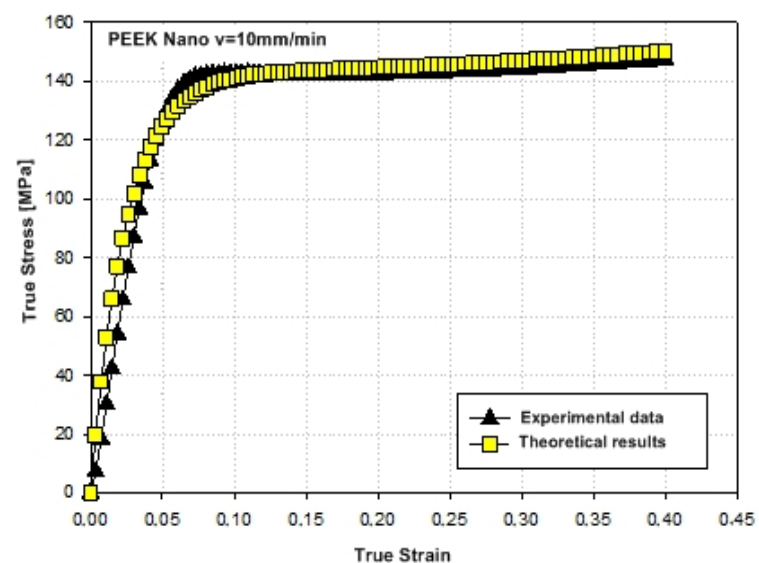

Fig. 5.Comparison between experimental and theoretical stress versus strain, for PEEK Nano, at the strain-rate of $2 \times 10^{-2} \mathrm{~s}^{-1}$

\begin{tabular}{|c|c|c|c|c|c|c|c|}
\hline \multirow{2}{*}{ Materials } & \multicolumn{7}{|c|}{ Parameters of G'Sell-Jonas model } \\
\cline { 2 - 8 } & $K$ & $w$ & $m$ & $a$ & $b$ & $h$ & $n$ \\
\hline PEEK & 141.1 & 28.27 & 0.015 & 1.27 & 24.2 & - & - \\
\hline $\begin{array}{c}\text { PEEK CF } \\
30\end{array}$ & 183.4 & 35.7 & 0.008 & - & - & - & - \\
\hline $\begin{array}{c}\text { PEEK } \\
\text { Nano }\end{array}$ & 156.3 & 41.4 & 0.023 & - & - & 0.3 & 2 \\
\hline
\end{tabular}

Tab. 1. Constitutive parameters of the flow curve

Neat PEEK shows a typical polymer yield point as compared to its composites, followed by a softening range, and a roughly straight sub domain up to 0.4 value of strain.

Due to the effect of the additives, the two composites (PEEK CF 30 and PEEK Nano) show a different behaviour related to the neat PEEK, and a larger viscoelastic sub domain is determined by smaller values of the $w$ parameter.

Carbon fibres and carbon nanotubes make maximal stress to increase, while the smallest sensitivity to the strain-rate can be noticed in the case of PEEK CF 30 composite ( $m$ takes smallest value). Also, it can be seen on the figures 4 and 5 that no softening range appears for PEEK CF 30 and PEEK Nano composites

\section{CONCLUSION}

The calculated constitutive parameters applied to G'SellJonas model describe fairly well the mechanical behavior of the materials tested, according to experimental data. Parameters values are valid for a function $\bar{\sigma}(\bar{\varepsilon} ; \dot{\bar{\varepsilon}})$ that describes the deformations for the three materials at strain- rates in the range $1 \times 10^{-3} \mathrm{~s}^{-1}-2 \times 10^{-2} \mathrm{~s}^{-1}$. The yield strength get highest value in the case of PEEK CF 30, while no significant increase was recorded for PEEK Nano composite.

For small deformations and high stress, the best behavior was noticed in the case of PEEK CF 30, owing the reinforcement with carbon fibers that enhances mechanical strength of material.

\section{ACKNOWLEDGEMENTS}

The work of Dan Trufasu and Aida Besnea was supported by Project SOP HRD - SIMBAD 6853, 1.5/S/15 - 01.10.2008

\section{REFERENCES}

G'Sell, C. (1988). Instabilités de déformation pendant l'étirage des polymères solides (Deformation instabilities during stretching of solid polymers). Revue de Physique Appliquée, Vol. 23, No. 6, 1085-1101, http://hal.archivesouvertes.fr/jpa-00245911/en/

Ogasawara, T.; Tsuda, T. \& Takeda, N. (2011). Stress-strain behavior of multi-walled carbon nanotube/PEEK composites. Composites Science and Technology, Vol. 71, No. 2, (January 2011) 73-78, ISSN 0266-3538

Rezgui, F.; G'Sell, C.; Dahoun, A.; Hiver, J.M. \& Sadoun, T. (2011). Plastic deformation of Low-Density Polyethylene reinforced with biodegradable polylactide, part 2: creep characterization and modeling. Polymer Engineering \& Science, Vol. 51, No. 1, (January 2011) 126-132, ISSN: $1548-2634$

Schoßig, M.; Bierogel, C.; Grellmann, W. \& Mecklenburg, T. (2008). Mechanical behavior of glass-fiber reinforced thermoplastic materials under high strain rates. Polymer testing, Vol. 27, No. 7, (October 2008) 893-900, ISSN 0142-9418

Zhang, Z.; Breidt, C.; Chang, L. \& Friedrich, K. (2004). Wear of PEEK composites related to their mechanical performances. Tribology International, Vol. 37, No. 3, (March 2004), 271-277, ISSN 0301-679X 